\title{
Monitoring tidal hydrology in coastal wetlands with the "Mini Buoy": applications for mangrove restoration
}

\author{
Thorsten Balke $^{1}$, Alejandra Vovides ${ }^{1}$, Christian Schwarz ${ }^{2}$, Gail L. Chmura ${ }^{3}$, Cai Ladd ${ }^{1}$, and Mohammad Basyuni ${ }^{4}$ \\ ${ }^{1}$ School of Geographical and Earth Sciences, University of Glasgow, Glasgow, G12 8QQ, United Kingdom \\ ${ }^{2}$ School of Marine Science and Policy, University of Delaware, Lewes, 19958 DE, United States \\ ${ }^{3}$ Department of Geography, Mc Gill University, Montreal, QX H3A 0B9, Canada \\ ${ }^{4}$ Department of Forestry, Faculty of Forestry, Universitas Sumatera Utara, Medan 20155, Indonesia
}

Correspondence: Thorsten Balke (thorsten.balke@glasgow.ac.uk)

Received: 4 November 2020 - Discussion started: 4 December 2020

Revised: 9 February 2021 - Accepted: 9 February 2021 - Published: 11 March 2021

\begin{abstract}
Acquiring in situ data of tidal flooding is key for the successful restoration planning of intertidal wetlands such as salt marshes and mangroves. However, monitoring spatially explicit inundation time series and tidal currents can be costly and technically challenging. With the increasing availability of low-cost sensors and data loggers, customized solutions can now be designed to monitor intertidal hydrodynamics with direct applications for restoration and management.

In this study, we present the design, calibration, and application of the "Mini Buoy", a low-cost underwater float containing an acceleration data logger for monitoring tidal inundation characteristics and current velocities derived from single-axis equilibrium acceleration (i.e. logger tilt).

The acceleration output of the Mini Buoys was calibrated against water-level and current-velocity data in the hypertidal Bay of Fundy, Canada, and in a tidally reconnected former aquaculture pond complex in North Sumatra, Indonesia. Key parameters, such as submersion time and current velocities during submergence, can be determined over several months using the Mini Buoy. An open-source application was developed to generate ecologically meaningful hydrological information from the Mini Buoy data for mangrove restoration planning. We present this specific SE Asian mangrove restoration application alongside a flexible concept design for the Mini Buoy to be customized for research and management of intertidal wetlands worldwide.
\end{abstract}

\section{Introduction}

\subsection{Tidal flooding and coastal wetlands}

Tidal flooding is the main driver of species distribution and ecosystem functioning in intertidal wetlands (i.e. salt marshes and mangroves). Inundation determines the composition of plant communities through physiological inundation and salt-tolerance limits, soil anoxia, and altered competitive ability along the tidal flooding gradient (Bockelmann et al., 2002; Jiménez et al., 1991; van Loon et al., 2007; Matthijs et al., 1999; Pennings and Callaway, 1992; Silvestri et al., 2005). Tidal currents can disperse propagules (Delgado et al., 2001; Koch et al., 2009; Van der Stocken et al., 2013; Wiehe, 1935) and dislodge seedlings when drag forces exceed the stability threshold of rooted seedlings (Balke et al., 2011, 2014; Wiehe, 1935; Xiao et al., 2016). Interactions between tidal currents and the friction created by vegetation (Bouma et al., 2013; Schwarz et al., 2018; Temmerman et al., 2007) determine the evolution of intertidal landscapes through flow routing and altered sedimentation patterns (i.e. biogeomorphic feedbacks). Monitoring flooding gradients and tidal currents is not only key to understanding intertidal wetland functioning but is also a prerequisite for the design and monitoring of successful restoration projects in the intertidal zone (Lewis, 2005; Primavera and Esteban, 2008; Wolters et al., 2005). Mangrove restoration projects in particular have shown low success rates due to the lack of hydrological site assessments prior to restoration (Primavera and Esteban, 2008; Wodehouse and Rayment, 2019). Here, we present the design, calibration, and application of 
a bottom-mounted underwater float equipped with an acceleration data logger (from here on referred to as the "Mini Buoy") to monitor inundation duration and current velocities in intertidal environments with a specific application for SE Asian mangrove restoration.

\subsection{Hydrological and hydrodynamic bottlenecks to mangrove restoration}

Assessing the local hydrology prior to mangrove restoration is needed to determine whether conditions are too harsh for seedlings to survive and need to be mitigated (Albers and Schmitt, 2015) or whether insufficient flooding may lead to hypersalinity or succession towards terrestrial plant communities (Lewis, 2005). One of the main reasons for mangrove deforestation in the past, and hence one of the major opportunities for mangrove restoration today, is aquaculture ponds (Dale et al., 2014; Primavera and Esteban, 2008). Breaching the embankments of such ponds, built within previous mangrove forests, is an effective way to restore mangrove forests. However, previous excavation of sediment and altered tidal channels and remaining weirs may have altered the hydrology. Hence spatially explicit monitoring of inundation durations is required prior to attempting mangrove restoration (Dale et al., 2014). Especially stagnant water and inhibited drainage can locally create restoration bottlenecks in abandoned tidal pond complexes. At hydrodynamically exposed sites, where current velocities are able to dislodge recently rooted mangrove propagules, inundation-free periods of several days provide a window of opportunity (WoO) to surpass critical establishment thresholds (Balke et al., 2011, 2014). WoO are particularly important to assess in unassisted restoration projects to predict suitability for natural colonization by mangrove pioneer species.

\subsection{Monitoring tidal inundation and currents}

Inundation frequency and duration of tidal wetlands are generally derived from nearby tide gauges or in situ pressuresensor deployments. The data are then projected onto digital elevation models or transects derived from levelling. Tidal current velocity is typically monitored using electromagnetic flow meters (EMFs), acoustic Doppler velocimeters (ADVs), or acoustic Doppler current profilers (ADCPs) (see, for example, Mullarney et al., 2017). The need for existing monitoring infrastructure and specialist equipment and knowledge means that capacity for hydrological and hydrodynamic monitoring may not always be readily available for restoration practitioners. Hydrodynamic time series data are also often limited in their duration due to the high demand for storage and battery capacity or due to concerns over theft or damage during storms. Hence long-term variability, rare disturbance events, or stochastic WoO in coastal wetlands are often missed.
Proisy et al. (2018) note that large-scale mangrove restoration across disused and abandoned aquaculture ponds requires the assessment of elevations and hydrological conditions in each individual pond, since conditions can differ greatly depending on the site history. Hydrological site assessments in such complex anthropogenic tidal landscapes can thus quickly become costly and time-demanding. Mangrove restoration manuals do acknowledge the need to assess site-specific tidal flooding and hydrodynamic exposure and propose practical "low-tech" solutions for their quantification. A manual published by the Mangrove Action Project, for example, advocates measuring the elevation of a restoration site (using optical levelling equipment or a hose water level) against known references such as local tide gauges or elevations of nearby mangrove stands (Lewis and Brown, 2014). Semi-quantitative methods to assess hydrodynamic exposure, such as gypsum clod cards, are also proposed (Lewis and Brown, 2014). These methods are low-cost and locally implementable, but not all are quantitative, scalable, or comparable across mangrove environments. We propose that monitoring tidal inundation and hydrodynamic exposure using accelerometer technology could be an affordable, globally available, and quantitative method to assess hydrological site suitability for mangrove restoration.

\subsection{Accelerometer technology to monitor tidal currents}

Accelerometer technology is widely used, from measuring shock and triggering safety air bags in the transport industry (MacDonald, 1990) to quantifying the physical activity of humans (Beanland et al., 2014; Passfield et al., 2017) and analysing particle movement in geosciences (Akeila et al., 2010). Equilibrium acceleration data from two axes relative to the gravity vector can be used for precise tilt measurements of objects. This principle is used in dip-current meters which relate the tilt of a bottom-mounted float with current velocities and the drag forces exerted on the float (Figurski et al., 2011; Hansen et al., 2017). A similar single-axis acceleration tilt calculation principle (i.e. the acceleration relative to the horizontal plane relates to the sine of the tilt angle) was applied here to determine inundation of the Mini Buoy and to correlate equilibrium acceleration of the Mini Buoy with current velocities (Fig. 1). For a detailed description of the individual forces acting on bottom-mounted floats, see Figurski et al. (2011). Commercial dip-current meters have recently become available; however, to the best of our knowledge, they do not routinely include the analysis of flooding characteristics for intertidal applications and are still costly compared to the described setup with off-the-shelf components. Moreover, commercial dip-current meters with a fixed calibration cannot be customized. Adding additional sensors (as shown here, for example, a temperature sensor) or changing the shape and size of the float and length of the tether offers flexibility for the application in different environments. The single-axis tilt calculation principle offers the benefit of re- 


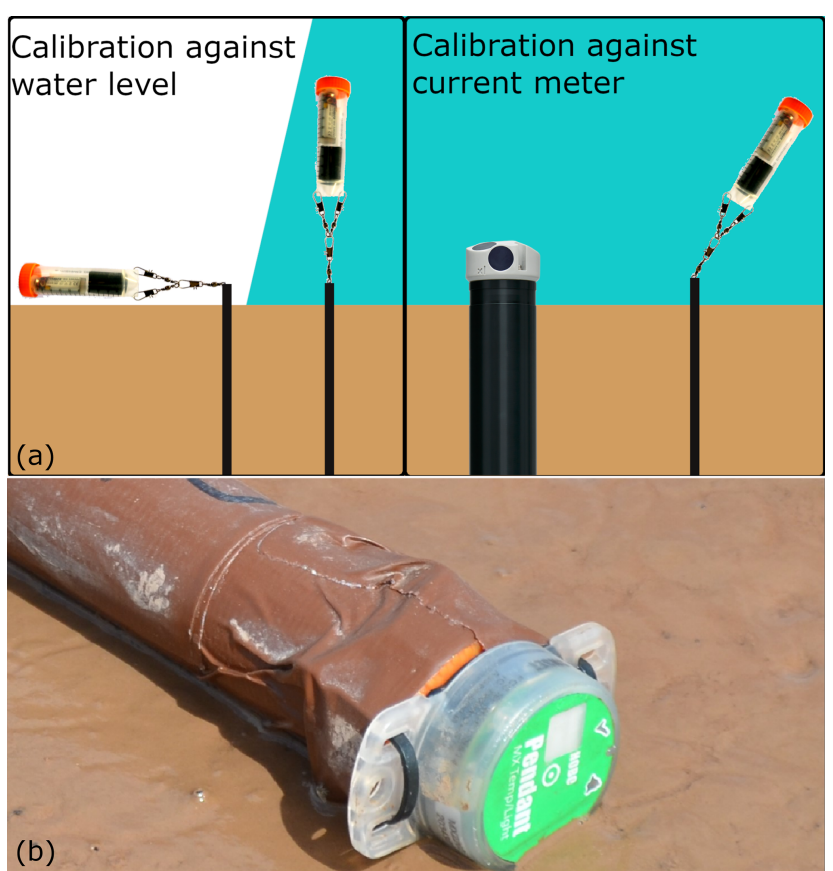

Figure 1. (a) Movements of a small bottom-mounted float (the Mini Buoy) equipped with an acceleration data logger during high and low tide. Single-axis equilibrium acceleration (i.e. tilt) of the buoy was calibrated against water-level and current-velocity data using an acoustic Doppler current meter (pictured). The Mini Buoy consists of a flat-bottom centrifuge tube which is tethered to the tidal flat using fishing swivels and a metal stake. The acceleration data logger is a self-contained unit with internal battery and storage. Single-axis equilibrium acceleration (with $y$-axis acceleration $=-1 g$ when vertical, i.e. flooded, and $0 g$ when horizontal, i.e. not flooded) correlates with the sine of the data logger tilt relative to the horizontal plane. (b) Additional data loggers for temperature and light can be attached on top of the Mini Buoy. Further details on dimensions and logger specifications are available in the Appendix.

duced data storage requirements (i.e. increased deployment durations) and the potential application of more economic sensors.

Here we describe the Mini Buoy, primarily as a design concept for the low-cost monitoring of abiotic conditions in periodically inundated intertidal ecosystems. We further present a fully calibrated Mini Buoy design with an opensource online data analysis application to assess tidal flooding (inundation and current velocities) for ecological mangrove restoration planning with reference to habitat requirements of SE Asian mangrove species.

\section{Methods}

\subsection{The Mini Buoy setup}

The Mini Buoy consists of three readily available offthe-shelf components: an acceleration data logger, a self- standing $50 \mathrm{~mL}$ centrifuge tube (CentriStar, Corning), and three fishing swivels (see Figs. 1a and A1 and Table A2 for a detailed description; overall weight $=42.3 \mathrm{~g}$, displaced volume $=70 \mathrm{~mL}$, and length of tube + swivels $=21.5 \mathrm{~cm}$ ). Additional loggers can fit on top of the tube such as the HOBO MX2202 temperature and light sensor (see photo in Fig. 1 as used in the Bay of Fundy deployment). The Mini Buoy is anchored near the sediment surface and will float up when submerged and dip into the current according to the velocity magnitude near the bed. The acceleration data logger inside the Mini Buoy records gravitational acceleration as Gforces $(g)$ along the three axes of the tube relative to the gravity vector. Only $y$-axis acceleration was used in this study; hence any single-axis acceleration logger can be used for the Mini-Buoy. The MSR 145 B4A accelerometer (MSR Electronics $\mathrm{GmbH}$, Switzerland) used in this study has a capacity of 2 million measurements and an internal rechargeable battery. The data recording for $x$-axis and $z$-axis acceleration can be inactivated to increase storage capacity of the device. The sensitivity of the logger was set to $2 g$. The USB connector of the logger was facing upward in the tube; hence $y$ acceleration was $0 g$ when the logger was stationary in a horizontal (not submerged) position and $-1 g$ when (submerged) in a vertical position (Fig. 1). The time-averaged (i.e. equilibrium) $y$-axis acceleration output of the sensor $\left(Y_{\text {acc }}\right)$ corresponds to the tilt angle $(\theta)$ of the sensor relative to the horizontal plane (i.e. orthogonal to the gravity vector) following Eq. (1):

$Y_{\text {acc }}[g]=-1 g \times \sin (\theta)$.

$Y$-axis acceleration was acquired every second for short-term deployments (several days) and every $10 \mathrm{~s}$ for long-term deployments (single deployments of approx. 5 months are possible). We have chosen the described setup as the loggers, tube, and tether are globally available, and the selected data logger itself has a waterproof housing and sufficiently large internal data storage for deployments across multiple springneap tidal cycles.

\subsection{Field sites}

\subsubsection{Bay of Fundy (Canada)}

A short-term deployment of $9 \mathrm{~d}$ using eight Mini Buoys (L1L8) measuring acceleration at $1 \mathrm{~Hz}$ was carried out along a tidal flat to salt marsh transect in the Bay of Fundy, Canada $\left(45^{\circ} 47^{\prime} 6.80^{\prime \prime} \mathrm{N}, 64^{\circ} 37^{\prime} 17.30^{\prime \prime} \mathrm{W}\right)$. The Mini Buoys in the Bay of Fundy were also fitted with a HOBO MX2202 temperature and light sensor on top of the centrifuge tube (Fig. 1b). Measurements commenced on 9 June and ended on 17 June 2018. A Nortek Aquadopp $300 \mathrm{~m}$ current meter was installed $5 \mathrm{~m}$ seaward of Mini Buoy L1 for calibration. In addition, a pressure sensor (In- Situ Rugged TROLL) measured continuously at $1 \mathrm{~Hz}$, and on-site barometric pressure correction was carried out using a second logger. The eleva- 
tions along the transect were surveyed using an Emlid Reach View differential GPS rover with real-time kinematic positioning. The vegetation along the transect was $<10 \mathrm{~cm}$ in height and sparse enough for the logger to rest horizontally on the sediment surface when not inundated (L4-L8 are located within the marsh). Metal rods were used to anchor the Mini Buoys in place. This site serves as a test of the Mini Buoy design concept in very energetic hypertidal conditions.

\subsubsection{North Sumatra (Indonesia)}

\section{Short-term deployment sites}

A short-term deployment of $7 \mathrm{~d}$ was carried out along the east coast of North Sumatra (Fig. 2b; Percut Sei Tuan, Deli Serdang) starting on 27 November 2019. A total of 15 Mini Buoys (B2-B16) measured acceleration at $1 \mathrm{~Hz}$ inside an abandoned, naturally recolonizing, aquaculture pond $\left(3^{\circ} 43^{\prime} 22.86^{\prime \prime} \mathrm{N}, 98^{\circ} 46^{\prime} 15.29^{\prime \prime} \mathrm{E}\right)$. This pond is connected through constructed tidal channels to the main estuary and partially recolonized by Avicennia spp., Rhizophora spp., and Nypa fruticans. This site was transformed into aquaculture ponds in 2002 and subsequently abandoned. One main channel directly connects the study pond to the surrounding ponds and the estuary through a previously breached embankment. The channel was equipped with an additional Mini Buoy (B1) which was calibrated using an upward-facing Nortek Aquadopp $300 \mathrm{~m}$ current meter located $5 \mathrm{~m}$ north of Mini Buoy B1 (Fig. 2b; see also "channel" deployment in Fig. 6). The logger elevations of B9, B11, B12, and B14 in relation to the pressure sensor of the current meter were established using a Leica optical level. An aerial image was acquired using a DJI Phantom 4, and Mini Buoy locations were mapped using ground targets. An additional short-term Mini Buoy was placed on a tidal flat facing the open coast directly seaward of colonizing Avicennia marina seedlings ("Open coast” deployment in Fig. $6\left(3^{\circ} 44^{\prime} 1.55^{\prime \prime} \mathrm{N}, 98^{\circ} 46^{\prime} 31.34^{\prime \prime} \mathrm{E}\right)$.

\section{Long-term deployment sites}

Long-term deployments of approximately $50 \mathrm{~d}$ were conducted at three locations: (i) North Sumatra at an abandoned pond in Percut Sei Tuan, where tidal regulation with a sluice system was still partially active (deployment "Abandoned pond 1" in Fig. 6: $3^{\circ} 43^{\prime} 33.77^{\prime \prime} \mathrm{N}, 98^{\circ} 46^{\prime} 22.70^{\prime \prime} \mathrm{E}$; 7 October 2019); (ii) at the Percut Sei Tuan short-term study site described above (see "long-term" logger nested within the short-term deployment in Fig. 2b), which was exposed to regular tidal inundation ("Abandoned pond 2" in Fig. 6: $3^{\circ} 43^{\prime} 23.86^{\prime \prime} \mathrm{N}, 98^{\circ} 46^{\prime} 14.78^{\prime \prime} \mathrm{E} ; 7$ October26 November 2019); and (iii) at a recent restoration site at Belawan with active planting of Rhizophora apiculata

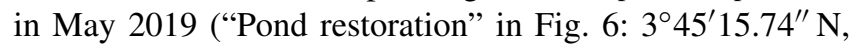
$98^{\circ} 42^{\prime} 22.43^{\prime \prime}$ E; 9 October-26 November 2019).

\subsection{Training dataset to predict Mini Buoy inundation}

Linear discriminant analysis (LDA) with R packages MASS (Venables and Ripley, 2002) and klaR (Weihs et al., 2005) was used to differentiate inundated time steps from noninundated time periods using the acceleration data. The LDA is a machine learning tool that requires a training dataset (i.e. inundation time series at the Mini Buoy location) to then predict inundation events for other Mini Buoys and time periods. This approach was chosen as it can be directly applied to other Mini-Buoy designs that may have different buoyancy, dimensions, and data loggers. Mini-Buoys closest to the Aquadopp current meter and pressure sensor (L2L5 at the Bay of Fundy and B9, B11, B12, and B14 in North Sumatra) were selected to generate a training dataset at 1 min resolution containing flooded and non-flooded classes based on water-level and elevation data. For North Sumatra, water-level data were linearly interpolated to $1 \mathrm{~min}$ frequency using the Aquadopp pressure sensor diagnostic output, and water-level data were generated directly from a separate pressure data logger at 1 min frequency at the Bay of Fundy. The Mini Buoys were considered "flooded" when fully submerged (i.e. bed elevation $+20 \mathrm{~cm}$ ). The LDA then separated and predicted flooded and non-flooded cases using 1 min median $y$ acceleration and the difference between the $1 \mathrm{~min} 75$ th and 25th percentile of the $y$ acceleration (i.e. the variability of $y$-axis measurements) as predictor variables. The klaR package provides apparent error rates (i.e. the proportion of observed cases incorrectly predicted), and additional cross-validation using LDA predictions for a subset of Mini Buoys was carried out. The generated LDAs were used to predict all Mini Buoy inundation classifications (L1-L8 and B2-B16) to create time series of inundation characteristics and subsequently predict current velocities.

\subsection{Mini-Buoy calibration against current velocity}

At both study sites an Aquadopp $300 \mathrm{~m}$ current meter (Nortek) was installed with the measurement head $20 \mathrm{~cm}$ above the sediment surface. The blanking distance was set to $35 \mathrm{~cm}$, and the device measured in diagnostic mode with 1025 sample bursts every hour at $1 \mathrm{~Hz}$ (internal sampling rate $=23 \mathrm{~Hz}$ ). Median $y$ acceleration over a $1 \mathrm{~min}$ period for both Mini Buoys (L1 at Bay of Fundy and B1 in North Sumatra) was correlated with the median current velocities for both horizontal velocity axes over a 1 min period.

The site- and design-specific calibration curves were further used to predict current velocities for all deployed Mini Buoys (Fig. 2). In order to separate individual high-tide events for each Mini Buoy, inundation events were separated whenever no inundation occurred for at least $100 \mathrm{~min}$. As partially inundated Mini Buoys during early phase of submergence or late stages of emergence may create inaccurate velocity predictions, a buffer time period at the start and end of each high tide was implemented. The first and last $10 \mathrm{~min}$ 

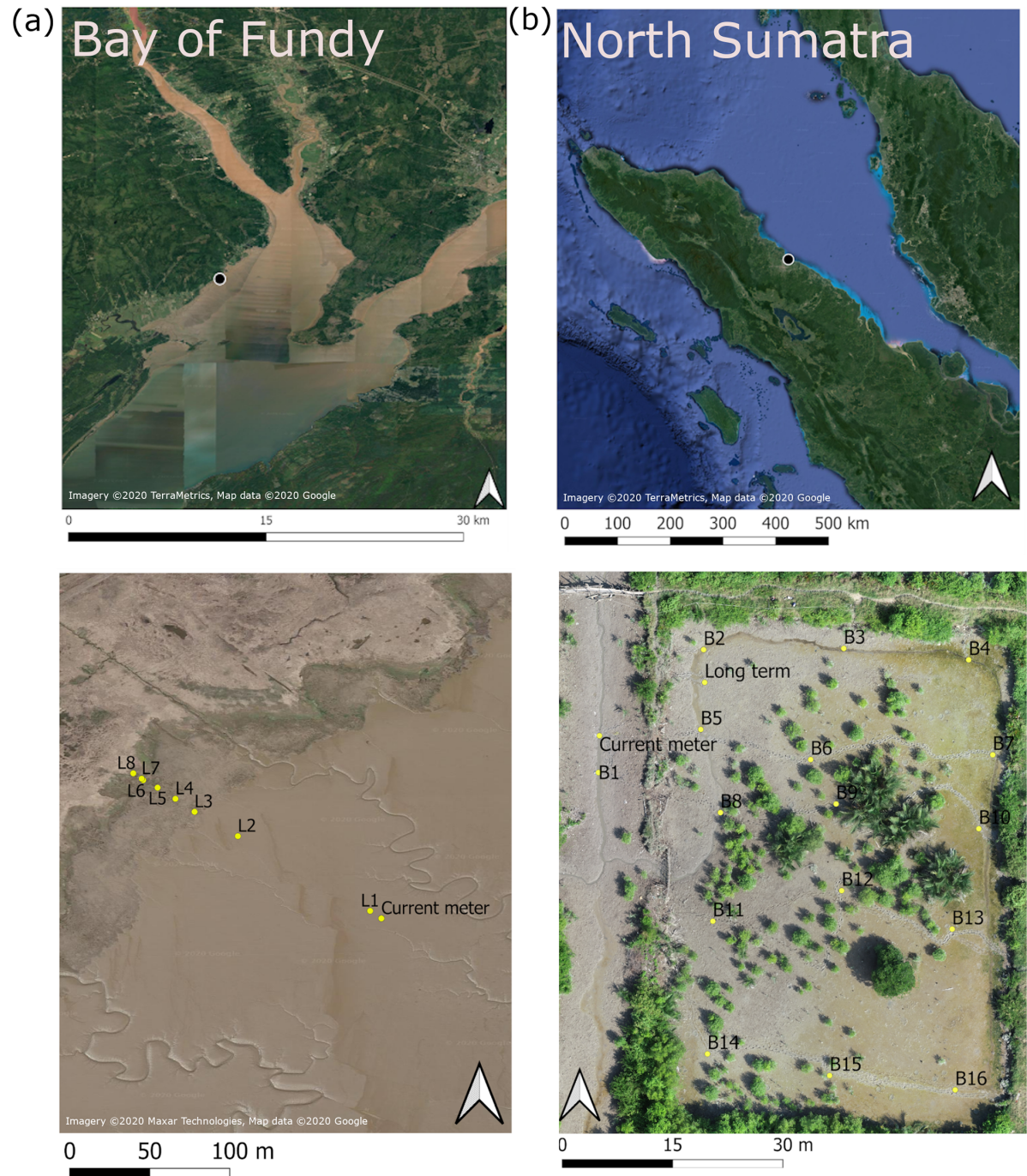

Figure 2. (a) The study sites in the Bay of Fundy, Canada, with eight Mini Buoys with a temperature and light sensor (see Fig. 1b) deployed along an elevational transect. L1 and L2 are located on the tidal flat, L3 is at the marsh edge, and L4-L8 are within the salt marsh (bottom left). (b) The short-term study site in Percut Sei Tuan, North Sumatra, Indonesia, with 16 Mini Buoys (B1-B16) deployed across an abandoned aquaculture pond that was naturally recolonized by mangrove plants (drone image on bottom right). Both study sites were equipped with a Nortek Aquadopp current meter close to L1 and B1 to calibrate the Mini Buoys. Maps were created using () QGIS.

of each predicted tide for Bay of Fundy data and $50 \mathrm{~min}$ for the North Sumatra time series were not used for velocity predictions. This buffer duration was based on the time it takes for the tide to rise and fall by $20 \mathrm{~cm}$ (i.e. the Mini Buoy height) at each site, as estimated from water-level measurements. Inundation durations were calculated from the predicted inundation categories using the LDA, and each high tide event was separated into two equal halves to separate approximate flood and ebb tides. Overall current velocities for the entire monitoring period were predicted as median values and 75th percentiles to reduce the influence of outliers (e.g. due to passing boats, waves, or turbulence).

\section{Results}

\subsection{Flooding and current-velocity calibration}

The LDA separated the Mini Buoy data in inundated and non-inundated time steps with apparent error rates of 0.008 for merged L2-L5 Mini Buoy data (Bay of Fundy) and of 0.015 for merged B9, B11, B12, and B14 Mini Buoy data (North Sumatra) (Fig. 3a). Using Mini Buoy data of L2 and L3 as a training dataset to predict L4 inundation classification with the LDA at 1 min intervals at the Bay of Fundy transect produced $1.57 \%$ false predictions. Cross-validating predictions with an LDA generated from B11 and B12 to predict B14 at the North Sumatra site produced $1.4 \%$ false 
predictions when validated against water-level classification. The variability of the $y$-axis acceleration within the $1 \mathrm{~min}$ time step (i.e. differences between the 75th and 25th percentile of $y$ acceleration) was different between both field sites. Percentile ranges of up to $0.5 \mathrm{~g}$ were recorded at the Bay of Fundy; the Mini Buoy within the tidal channel in North Sumatra showed values of up to $0.08 g$. This is likely attributed to the more dynamic conditions at the Bay of Fundy, where significant wave heights calculated from the Aquadopp data reached $0.73 \mathrm{~m}$ during the monitoring period. Mini Buoys deployed further away from the pressure sensor were not considered for calibration as the local water levels may be influenced by local flooding and draining pattern through tidal channels.

Median current velocities for 1 min time steps at both locations correlated with median $y$-axis acceleration over the same time step and were best described using a third-order polynomial regression rather than a sine function (Fig. 3b). The polynomial fit may be attributed to a change in the proportion of the sampled velocity profile (i.e. the Mini Buoy dips into faster currents and hence stays closer to the bed when compared to low currents). The calibration curves for both field sites show that current velocities above $\sim 0.1 \mathrm{~m} \mathrm{~s}^{-1}$ could be measured by the Mini Buoy. The Bay of Fundy Mini Buoys fitted with a temperature and light logger showed a slightly higher sensitivity to low velocities (likely due to reduced buoyancy). Velocities measured at the Bay of Fundy reached up to $0.5 \mathrm{~m} \mathrm{~s}^{-1}$, whereas velocities at the North Sumatra tidal channel stayed generally below $0.4 \mathrm{~m} \mathrm{~s}^{-1}$. After applying the identification of individual tides and removing the buffer time periods at the start and end of each inundation event, continuous predictions of velocities were achieved (see Fig. 4 for examples of tidal current predictions). Averaged tidal current predictions and inundation durations were plotted across the elevation transect at the Bay of Fundy and showed a rapid decrease in median current velocities with increasing distance from the main channel (Fig. 5a). An increase in median current velocities was observed at the edge of the highest salt marsh terrace compared to the lower marsh elevations. Animations of the predicted inundation events and current velocities are available from the online materials (https://zenodo.org/record/4521304, last access: 9 March 2021).

Predicted median current velocities within the disused aquaculture pond at the North Sumatra study site mostly ranged between 0.09 and $0.12 \mathrm{~m} \mathrm{~s}^{-1}$ and were thus near the detection limit of this Mini Buoy design. Two buoys, within the channel filling and draining the abandoned aquaculture pond, B5 and B8, reached median velocities of $0.13 \mathrm{~m} \mathrm{~s}^{-1}$ (see Fig. 4 for B8 predictions). Inundation duration ranged between 292 and $635 \mathrm{~min} \mathrm{~d}^{-1}$ within the abandoned pond (Fig. 5b). The spatial pattern of inundation duration showed that drainage occurred via the tidal creek in the northern part of the pond (see animation of inundation events online at https://zenodo.org/record/4521304, last ac- cess: 9 March 2021). The shorter inundation durations generally corresponded to the more densely recolonized areas of the abandoned pond, whereas the southeast corner of the pond and the channel with inundation durations exceeding $460 \mathrm{~min}^{-1}$ showed a lack of recolonization by mangrove trees (Fig. 5b). However, these are short-term assessments to test the Mini Buoy performance, and further investigation into inundation durations should be carried out across spring-neap cycles as described in Sect. 3.2.

All Mini Buoy acceleration data, temperature and light data, and Aquadopp data are available online (https://zenodo. org/record/4521304, last access: 9 March 2021).

\subsection{Hydrological site assessments for mangrove restoration in SE Asia using the Mini Buoy application}

\subsubsection{Development of the Mini Buoy R shiny application}

An online app, using the $\mathrm{R}$ package shiny (Chang et al., 2020), was created as a quick and easy way to assess local hydrological site conditions prior to restoration of mangroves with reference to requirements of SE Asian mangrove species. Acceleration data acquisition can be reduced to $10 \mathrm{~s}$ intervals to allow for longer deployment periods across spring-neap tidal cycles and seasons. For calibration of lowfrequency data, Mini Buoys B1, B11, and B12 were resampled at $10 \mathrm{~s}$ intervals. The same analyses for inundation predictions using the LDA and correlation against current velocities (as described above) were carried out over $15 \mathrm{~min}$ time periods. Mini Buoys were considered submerged in the calibration time series when measured water levels were above the Mini Buoy for the entire $15 \mathrm{~min}$ period. Instead of the LDA, a fixed acceleration threshold was applied to differentiate between flooded and non-flooded time steps. This threshold allows for the use of the Mini Buoy and the R shiny application without the need to load training datasets and was informed by the results of the LDA. The fixed threshold predictions were further cross-validated against the LDA predictions for Mini Buoys B11 and B12.

The LDA using $10 \mathrm{~s}$ interval acceleration data for $15 \mathrm{~min}$ time step predictions achieved an apparent error rate of 0.017 for Mini Buoys B11 and B12 (Fig. A3). A fixed threshold of $-0.5 \mathrm{~g}$ median $y$-axis acceleration to separate inundated and non-inundated events was applied to replace the LDA predictions. With a fixed threshold, inundation events were wrongly classified $2.49 \%$ of the time when compared with LDA predictions for buoys B11 and B12. Correlation between $y$ acceleration measured by the Mini Buoys and median current velocities measured by the Aquadopp current meter in $15 \mathrm{~min}$ intervals was best explained using linear regression $\left(V_{\text {cur }}=1.173+1.059 \cdot Y_{\text {acc }}, R_{\text {adj }}=0.7724, P<\right.$ $0.05)$. This low-frequency calibration matches the calibration 
(a)

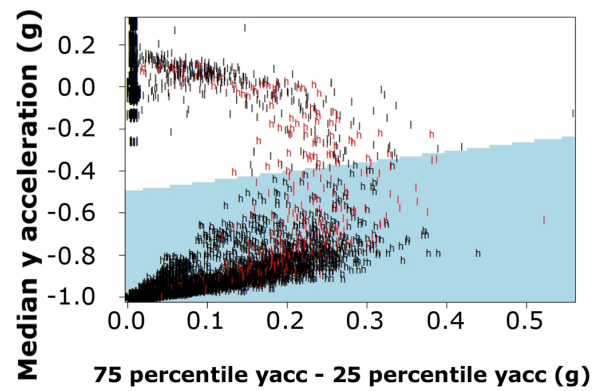

(b)

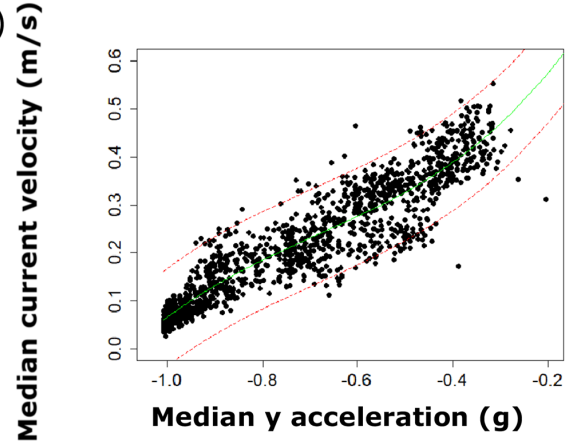

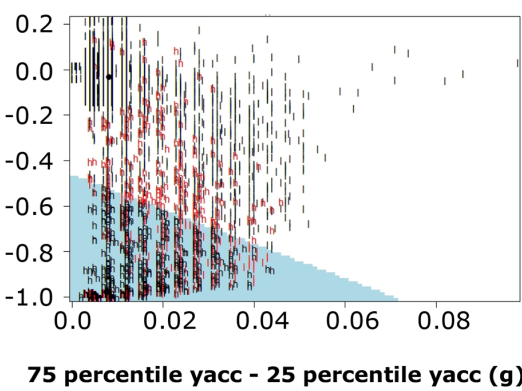

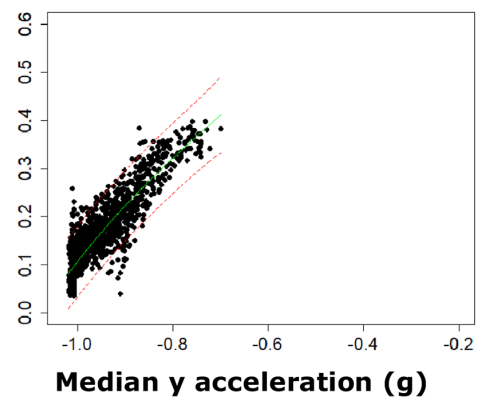

Figure 3. Training data for the Mini Buoy calibration at both study sites. (a) Linear discriminant analysis (LDA) with prediction of flooded and non-flooded time steps of L2-L5 (Bay of Fundy, left) and B9, B11, B12, and B14 (North Sumatra, right) based on acceleration data and validated against measured water levels. The error rate of the LDA for the Bay of Fundy was 0.008 and for North Sumatra 0.015 (1 is low tide, $\mathrm{h}$ is high tide, and red letters are false predictions). The blue-shaded area indicates the range of values for which inundation is predicted by the LDA. The LDA was then used to predict inundation events for all Mini Boys. (b) Polynomial regression provided the best fit for the median $y$-axis acceleration $\left[Y_{\text {acc }}(\mathrm{g})\right]$ against the measured current velocity $\left[V_{\text {cur }}\left(\mathrm{m} \mathrm{s}^{-1}\right)\right]$ for 1 min intervals at both study sites. L1 Bay of Fundy: $V_{\mathrm{cur}}=Y_{\mathrm{acc}} 0.8812+\left(1.9209 \cdot Y_{\mathrm{acc}}\right)+\left((2.1394) \cdot Y_{\mathrm{acc} 2}\right)+\left((1.0344) \cdot Y_{\mathrm{acc} 3}\right), R_{\mathrm{adj}}^{2}=0.84, P<0.05$; B1 North Sumatra: function $V_{\mathrm{cur}}=Y_{\mathrm{acc}} 1.488+\left((2.893) \cdot Y_{\mathrm{acc}}\right)+\left((2.921) \cdot Y_{\mathrm{acc} 2}\right)+\left((1.410) \cdot Y_{\mathrm{acc} 3}\right), R_{\mathrm{adj}}^{2}=0.79, P<0.05$. Dotted red lines show the $95 \%$ prediction intervals. Note that the Mini Buoy design differs slightly between both case studies as the Bay of Fundy design has an additional temperature and light logger attached.

against $1 \mathrm{~Hz}$ acceleration data for values within the calibration dataset (Fig. A3).

The R shiny application calculates inundation and currentvelocity statistics for the entire monitoring period: average high tide duration $(\mathrm{min})$, average flooding duration $\left(\min \mathrm{d}^{-1}\right)$, flooding frequency $\left(\mathrm{d}^{-1}\right)$, maximum duration of $\mathrm{WoO}(\mathrm{d})$ equal to the longest inundation-free period, median current velocity $\left(\mathrm{m} \mathrm{s}^{-1}\right), 75$ th percentile current velocity $\left(\mathrm{m} \mathrm{s}^{-1}\right)$, and difference of flood-ebb median velocity $\left(\mathrm{m} \mathrm{s}^{-1}\right)$. The $\mathrm{R}$ shiny application separates individual inundation events (i.e. high tides) using a minimum inundation-free period of $100 \mathrm{~min}$ and removes the first and last $60 \mathrm{~min}$ of each inundation event for current-velocity predictions to avoid misinterpretation of velocities in very shallow or stagnant water. The application also allows for a comparison with a second Mini Buoy to assess differences in conditions between a restoration target site and a reference site which has the desired conditions/habitat (i.e. previously successful restoration site or site with natural colonization of the desired species). The R shiny app code and a Mini Buoy handbook for logger programming, field deployment, and data analysis are available via GitHub. The app can also be used directly online via https://mangroverestoration. shinyapps.io/MiniBuoyApp/ (last access: 9 March 2021).

\subsubsection{Application of the Mini Buoy and the R shiny application}

This 15 min fixed threshold analysis as described above was implemented in the $\mathrm{R}$ shiny app to allow for deployment over longer durations and without calibration or training datasets and is aimed at mangrove restoration practitioners in SE Asia. We applied the Mini Buoy and the R shiny app across five different mangrove settings in North Sumatra (Fig. 6, Table 1). None of the deployments on tidal flats within abandoned aquaculture ponds (Abandoned pond 1, Abandoned pond 2, and Pond restoration site deployments) recorded median current velocities or 75 th percentile velocities above the detection limit. Only the short-term open coast and the tidal channel deployments showed 75th percentile velocities of up to 0.2 and $0.17 \mathrm{~m} \mathrm{~s}^{-1}$, respectively. The Abandoned pond 1 site had prolonged periods of stagnant water (i.e. low-frequency and long inundation periods) due to a sluice system partially in operation during the mon- 

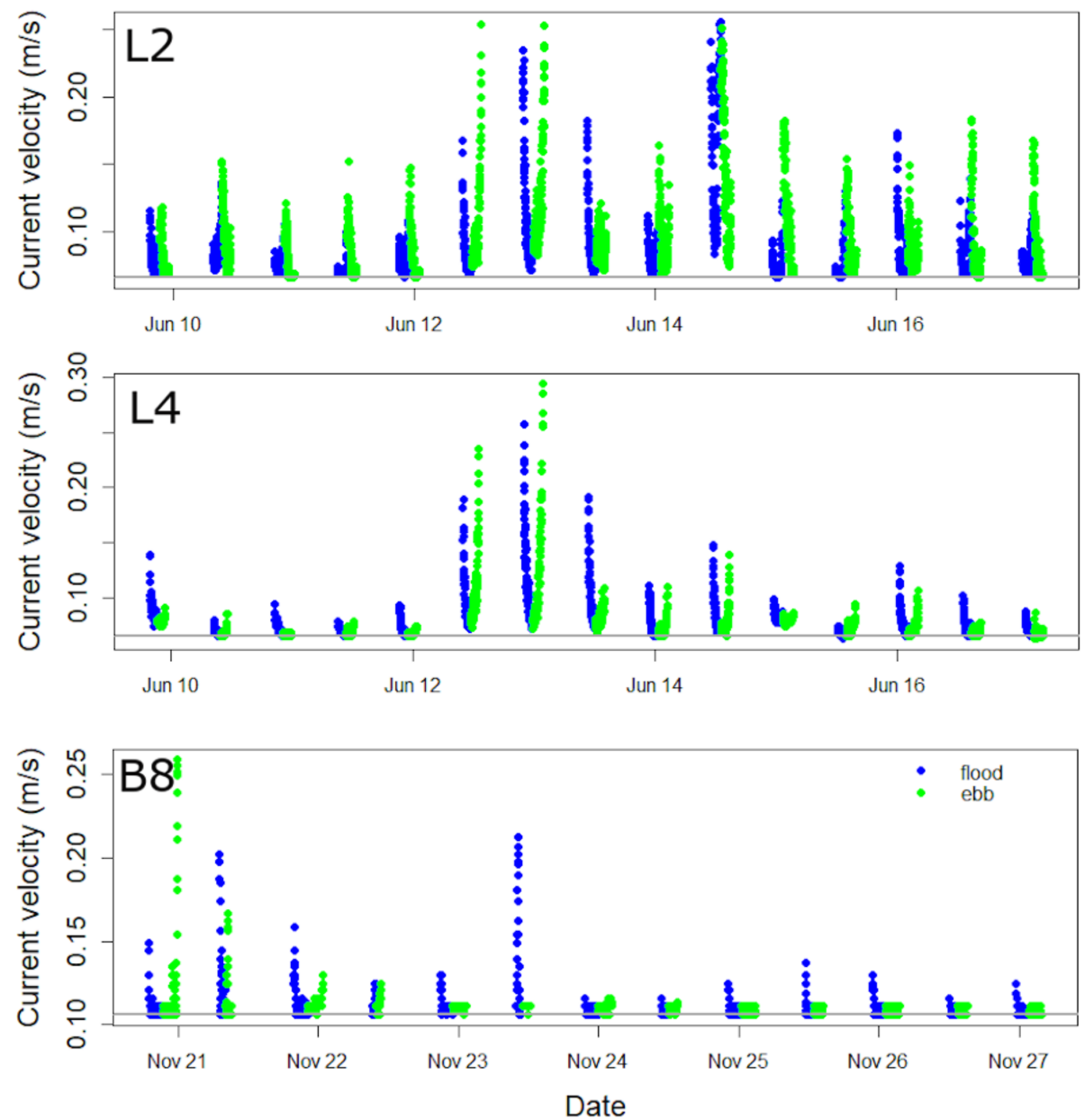

Figure 4. Examples of predicted current velocities during predicted inundation events for L2, L4, and B8 using the LDA (Fig. 3a) for inundation and regression analysis for velocity predictions (Fig. 3b). Colours denote the first and second half of the inundation time period (approx. flood and ebb tide), and the grey line indicates the detection threshold (i.e. Bay of Fundy (L2, L3) $=0.06 \mathrm{~m} \mathrm{~s}^{-1}$, North Sumatra $(\mathrm{B} 8)=0.106 \mathrm{~m} \mathrm{~s}^{-1}$; see Fig. 3b).

itoring period, whereas Abandoned pond 2 (i.e. "long-term" in Fig. 2) and the Pond restoration site could freely flood and drain through openings in the embankment. Only the Pond restoration site showed inundation-free WoO for more than two consecutive tides during the monitoring period.

\section{Discussion}

We successfully designed and calibrated the Mini Buoy, a small bottom-mounted float equipped with acceleration data logger, in contrasting intertidal environments. We further developed the Mini Buoy into a ready-to-use tool for mangrove restoration hydrological site assessments with a focus on disused aquaculture ponds and unvegetated tidal flats with reference to SE Asian mangrove species. This study (i) provides a design concept for low-cost monitoring of abiotic parameters in intertidal environments and (ii) enables practitioners to directly implement the Mini Buoy using an R shiny application in mangrove restoration, rehabilitation, and creation projects in SE Asia. This application can be easily customized to other regions with different species requirements and flooding characteristics. Calibrating the acceleration data of the Mini Buoy against water-level and current-velocity data showed that current velocities in excess of $0.1 \mathrm{~m} \mathrm{~s}^{-1}$ $\left(>0.06 \mathrm{~m} \mathrm{~s}^{-1}\right.$ with added temperature and light loggers at the Bay of Fundy) could be detected. Inundation events could be correctly identified using the Mini Buoy, with misclassifications below $1.6 \%$ and $2.5 \%$ when using a machine learning approach or a fixed vertical acceleration threshold respectively. With measurement intervals of $10 \mathrm{~s}$, the Mini Buoys as described here can be deployed for several months before data retrieval and battery recharging becomes necessary (the authors have successfully deployed the Mini Buoy for $164 \mathrm{~d}$ in a separate study using the design presented here). Whilst the Mini Buoys were able to represent a wide range of flood-ebb conditions, the current design has a limited capac- 


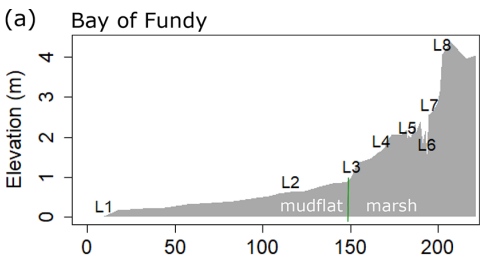

(b) North Sumatra
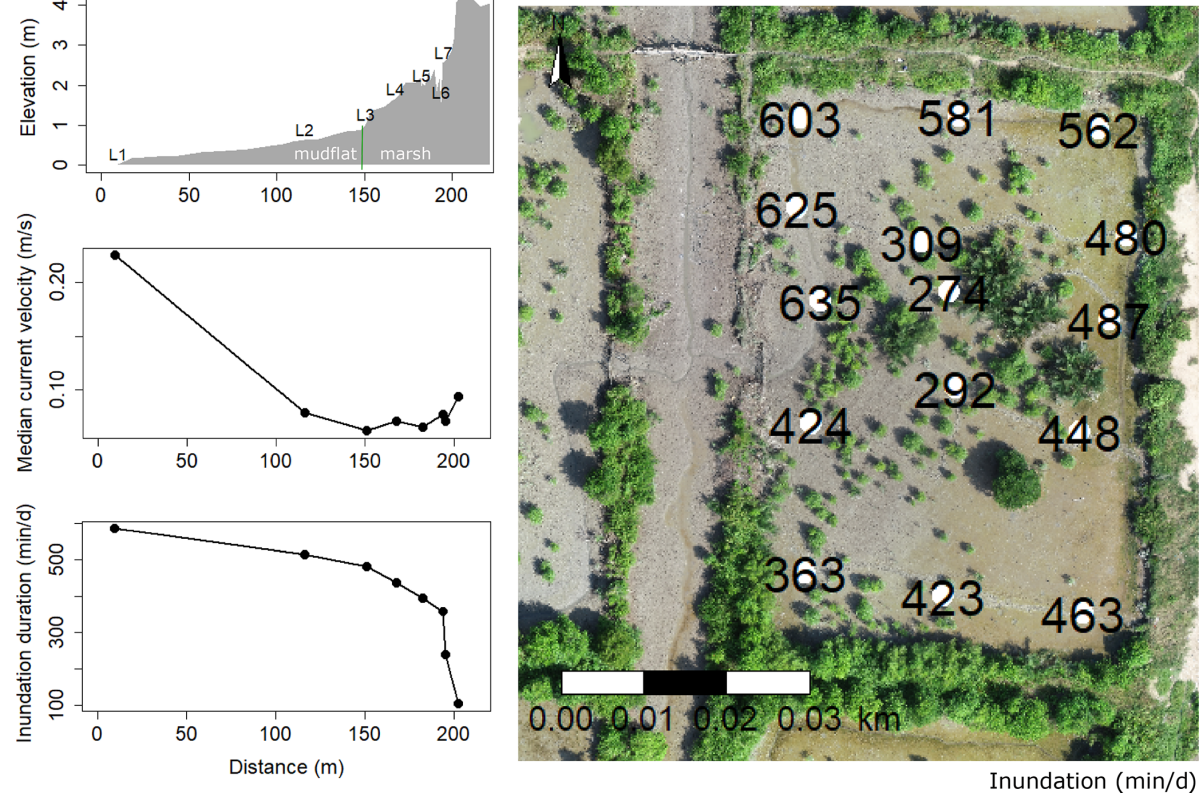

Figure 5. (a) Summary of predicted median current velocities and inundation duration for the entire monitoring duration (based on 1 min aggregated data) along the elevational gradient of the terraced salt marsh at the Bay of Fundy. (b) Inundation duration (min $\mathrm{d}^{-1}$ ) at the logger locations at the North Sumatra field site.

Table 1. Summary of site characteristics in North Sumatra using the Mini Buoy and the R shiny application. Note that "Abandoned pond 2" corresponds with the long-term location, and "Channel" corresponds with B1 in Fig. 2. Only "Open coast" and "Channel" show current velocities above the detection threshold. At the Abandoned pond 1 site a sluice system was partially in operation, leading to prolonged non-tidal flooding.

\begin{tabular}{|c|c|c|c|c|c|}
\hline Indicator & $\begin{array}{l}\text { Open } \\
\text { coast }\end{array}$ & Abandoned pond 1 & Abandoned pond 2 & Restoration & Channel \\
\hline Monitoring period (d) & 6.25 & 50.15 & 50.64 & 47.45 & 6.64 \\
\hline Average high tide duration (min) & 310.0 & 6492.0 & 282.3 & 218.2 & 343.8 \\
\hline Flooding frequency $\left(\mathrm{d}^{-1}\right)$ & 1.92 & 0.20 & 1.90 & 1.60 & 1.96 \\
\hline Maximum duration of WoO (d) & 0.36 & 0.91 & 0.84 & 3.64 & 0.34 \\
\hline Average flooding duration $\left(\min \mathrm{d}^{-1}\right)$ & 624.0 & 1298.5 & 556.8 & 373.3 & 702.9 \\
\hline Median current velocity $\left(\mathrm{m} \mathrm{s}^{-1}\right)$ & 0.14 & 0.11 & 0.11 & 0.09 & 0.13 \\
\hline 75th percentile velocity $\left(\mathrm{m} \mathrm{s}^{-1}\right)$ & 0.20 & 0.11 & 0.11 & 0.09 & 0.17 \\
\hline Flood-ebb median velocity $\left(\mathrm{m} \mathrm{s}^{-1}\right)$ & 0.01 & 0.00 & 0.00 & 0.00 & -0.01 \\
\hline
\end{tabular}

ity to measure low current velocities $\left(<0.1 \mathrm{~m} \mathrm{~s}^{-1}\right)$ and cannot make current-velocity predictions when the Mini Buoy is partially submerged (i.e. when water depths are below or around $20 \mathrm{~cm}$ ). The latter issue is resolved in the R shiny app by implementing an algorithm that detects individual inundation events and can identify non-tidal flooding events (e.g. due to sluice gate operations). Moreover, a buffer period around the start and end of each inundation ( $1 \mathrm{~h}$ in the $\mathrm{R}$ shiny app) is deleted to ensure that no erroneous current-velocity predictions for partially inundated loggers are made. Despite the lower accuracy of current-velocity information provided by the Mini Buoys compared to conventional hydrodynamic monitoring equipment, the low costs and quick direct deploy- ment and analysis (e.g. no levelling or specialist hydrological knowledge required) make this a suitable tool to assess hydrological site conditions at ecologically relevant scales. Additional loggers used in combination with the Mini Buoy can provide further insight into the temporal variability of abiotic conditions in combination with tidal flooding, for example in water quality studies (see flood and ebb temperature plot in Fig. A4). Calibrations in two very contrasting conditions (i.e. Bay of Fundy and North Sumatra) showed that the concept design is robust and easy to implement, even in strong currents and humid and hot climates and on soft muddy tidal flats. We demonstrated that the single-axis acceleration tilt calculation principle is of sufficient accuracy to identify eco- 

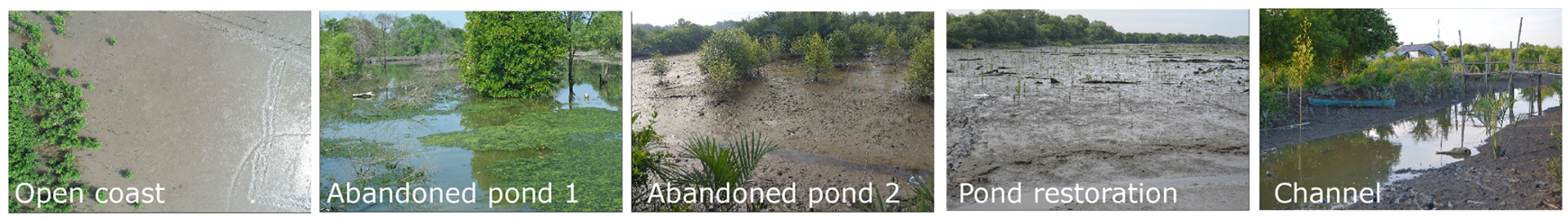

Figure 6. Photographs of deployment sites in North Sumatra.

logically relevant inundation and current-velocity information. Hence it is possible to reduce the costs of the Mini Buoy even further.

The primary information that the Mini Buoys provide is in situ flooding characteristics. These data can be compared to species-specific flooding thresholds from the literature. Van Loon et al. (2007), for example, estimated from a 1month flooding time series in the Mekong delta that flooding duration was between 800 and $400 \mathrm{~min}^{-1}$ for mangrove pioneers Avicennia spp. and Sonneratia spp., whereas the Rhizophora spp.-Ceriops spp.-Bruguiera spp. zone had $400-100 \mathrm{~min}^{-1}$ inundation durations on average. In addition to the physiological tolerance to flooding of established plants, mangrove propagules of Avicennia spp. require approximately $1-5$ inundation-free days to sufficiently root against dislodgement by the tide on bare tidal flats (i.e. WoO) (Balke et al., 2015). The stronger the hydrodynamic forcing upon first submergence, the longer the required $\mathrm{WoO}$ (i.e. the longer the roots required to stay anchored). The Mini Buoy is well suited as a tool to identify $\mathrm{WoO}$ as it measures inundation and hydrodynamic forcing directly on the tidal flat where new establishment may occur. The Mini Buoy can be further customized to include the detection of very shallow inundation events on tidal flats, for example to study propagule dispersal. Whereas WoO may be very stochastic and require deployment across seasons or even years to detect, average inundation conditions and velocities can be adequately estimated with monitoring across one or more spring-neap tidal cycle ( $>15$ d). Seasonal variability of conditions, especially with respect to the fruiting season of the desired species, should be accounted for where possible. To allow for a first rapid assessment of hydrological site suitability without expert knowledge and with a single Mini Buoy, the R shiny app contains several warning/interpretation messages related to SE Asian mangrove habitat suitability. For general site unsuitability (WoO $<1 \mathrm{~d}$ and for inundation durations $>800$ or $\left.<100 \operatorname{min~}^{-1}\right)$, warning messages will appear. Velocities are classified as low $\left(\leq 15 \mathrm{~cm} \mathrm{~s}^{-1}\right)$ and high $\left(>15 \mathrm{~cm} \mathrm{~s}^{-1}\right)$ to allow for a first estimation of hydrodynamic exposure. Warning messages will also appear where measurements do not cover spring and neap tidal cycles (i.e. are shorter than $15 \mathrm{~d}$ ). For more detailed single-deployment approaches, Mini Buoy data could be combined with a parameterized model of WoO of the local pioneer species, including root-growth rates and stability thresholds (Balke et al., 2014, 2015). Wave exposure could be included in site suitability assessments for wave exposed tidal flats; however, such sites are generally not recommended for restoration in the first place due to low success rates (Wodehouse and Rayment, 2019).

Our mangrove site comparison (Fig. 6, Table 1) using the Mini Buoys demonstrated how hydrological site conditions can vary locally. Abandoned pond 1 was the only site which exceeded the $800 \mathrm{~min} \mathrm{~d}^{-1}$ inundation threshold due to a temporarily closed sluice gate in the second half of the monitoring period. Hence the data from the Mini Buoy suggested that the remaining mangrove trees in Abandoned pond 1 (see photo in Fig. 6) will die off if the present flooding regime is maintained. Flooding duration in the Abandoned pond 2 site was generally suitable for mangrove pioneer colonization, and current velocities were below the detection limit. This was corroborated by the recent establishment of Avicennia spp. saplings and trees at the site. The Pond restoration site assessment confirmed that previously planted $R h i$ zophora apiculata at this site is likely to survive as the flooding duration is slightly below $400 \mathrm{~min}^{-1}$, and no significant current velocities were detected. This was the only site where WoO of $>1 \mathrm{~d}$ were detected during the monitoring period, which suggests that additional natural colonization could be expected if propagule dispersal is not hindered. The predicted current velocities of the "Open coast" tidal flat location (Table 1) showed the typical tidal pattern with flood, slack, and ebb tides (see R shiny example in the Zenodo repository).

Physiological tolerance to tidal inundation and establishment thresholds of mangroves also depend on other environmental factors such as soil anoxia, soil porewater salinity, bioturbation, and microclimate (Krauss et al., 2008). These factors may enhance or restrict the flooding tolerance of mangrove seedlings and trees at a given location. We therefore advocate the deployment of two Mini Buoys in tandem (as implemented in the $\mathrm{R}$ shiny application) in order to generate site-specific physiological thresholds, rather than rely on published information alone. This is especially recommended during short-term deployments over single springneap cycles. One Mini Buoy monitoring the conditions at the target restoration site can be compared to Mini Buoy data from a local reference site with the desired conditions and plant community. This has several benefits: (i) the reference site will likely experience the same regional stochastic variation in water levels (i.e. wind setup) over the monitoring 
period, (ii) the reference site will have the same local species pool, and (iii) the reference site will have similar edaphic soil conditions. Reference sites should show recent seedling establishment of the desired species as conditions suitable for seedling establishment are not equal to conditions required for survival of mature mangrove trees (Krauss et al., 2008). An example of the $\mathrm{R}$ shiny application output for a comparative deployment between is provided in the Zenodo repository.

\section{Conclusions}

With this study we were able to show that low-cost monitoring of hydrological conditions in intertidal environments (inundation and current velocities) across multiple springneap tidal cycles is possible using single-axis accelerometer technology and readily available materials for an underwater float (i.e. the Mini Buoy). Whereas this approach can be a useful tool in coastal research, we especially highlight the Mini Buoy as a stand-alone tool for easy-to-implement hydrological site suitability assessments prior to mangrove restoration. The Mini Buoy can be globally implemented as a standard for mangrove restoration site assessments as it is low-cost, easy to transport across borders, difficult to spot on the tidal flat, and not prone to storm damage as it is close to the ground and does not require specialist knowledge in coastal engineering or data analysis. Especially in the complex hydrological networks of abandoned aquaculture ponds in SE Asia, the Mini Buoy has the potential to efficiently assess site- and pond-specific conditions with only a few Mini Buoys rotated around the site. Learning from past mistakes in mangrove restoration, where a lack of hydrological site assessments has led to very low restoration success rates (Dale et al., 2014; Kodikara et al., 2017; Zaldivar-Jimenez et al., 2010), this new affordable and easy-to-implement technology will be able to assist urgently needed upscaling of future mangrove rehabilitation efforts (Worthington and Spalding, 2018). 


\section{Appendix A}

Table A1. Components of the Mini Buoy (without temperature and light loggers).

\begin{tabular}{llr}
\hline Item & Size & Weight \\
\hline Corning ${ }^{\circledR}$ 50 mL PP centrifuge tubes, self-standing CentriStar ${ }^{\mathrm{TM}}$ & $114.9 \mathrm{~mm}(\mathrm{~L})$ & $14.6 \mathrm{~g}$ \\
Accelerometer MSR 145 B4A (MSR Electronics GmbH, Switzerland) & $20 \times 14 \times 62 \mathrm{~mm}(W \times H \times L)$ & $18 \mathrm{~g}$ \\
3x Interlock snap fishing swivel with barrel (\#1) & $55 \mathrm{~mm}(\mathrm{~L})$ & $1.9 \mathrm{~g}$ \\
Foam to insert at bottom of logger, plastic bag to wrap accelerometer, tape, silicone seal & various & $<4 \mathrm{~g}$ \\
\hline Total & & $42.3 \mathrm{~g}$
\end{tabular}

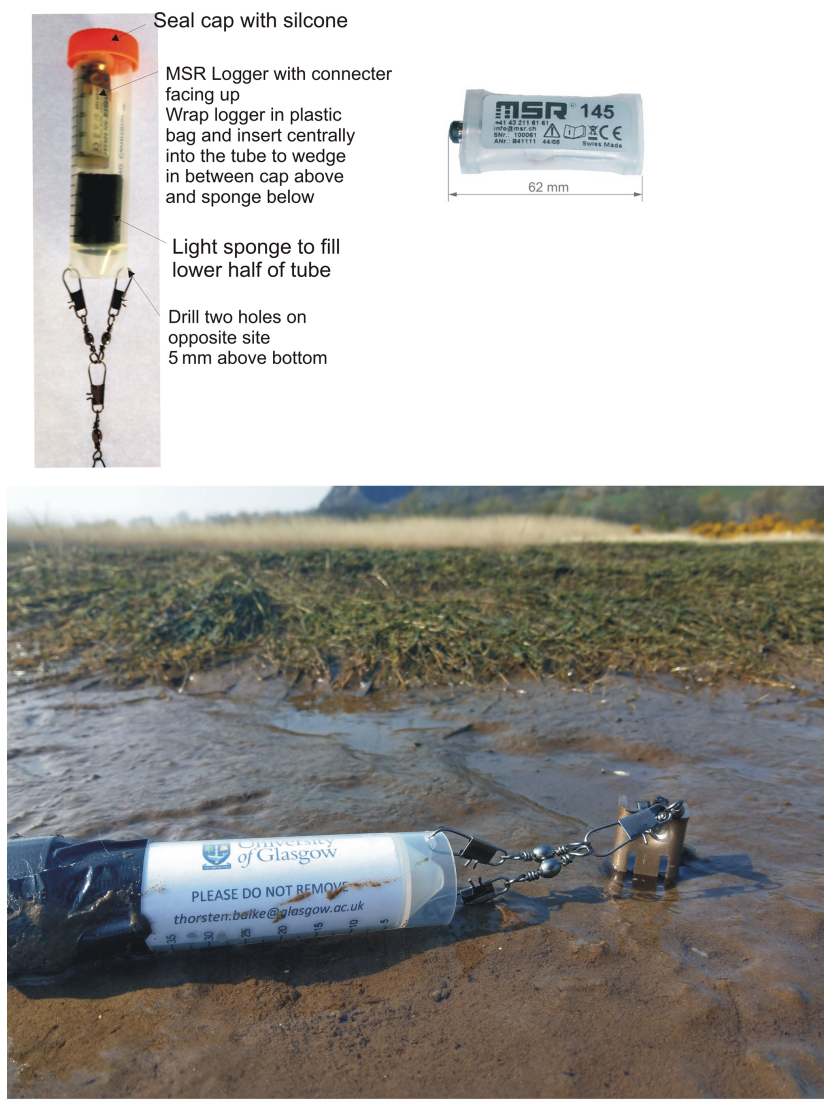

Fix logger to metal stake, protruding $<1 \mathrm{~cm}$ from tidal flat sediment

Figure A1. Mini Buoy components and installation. 

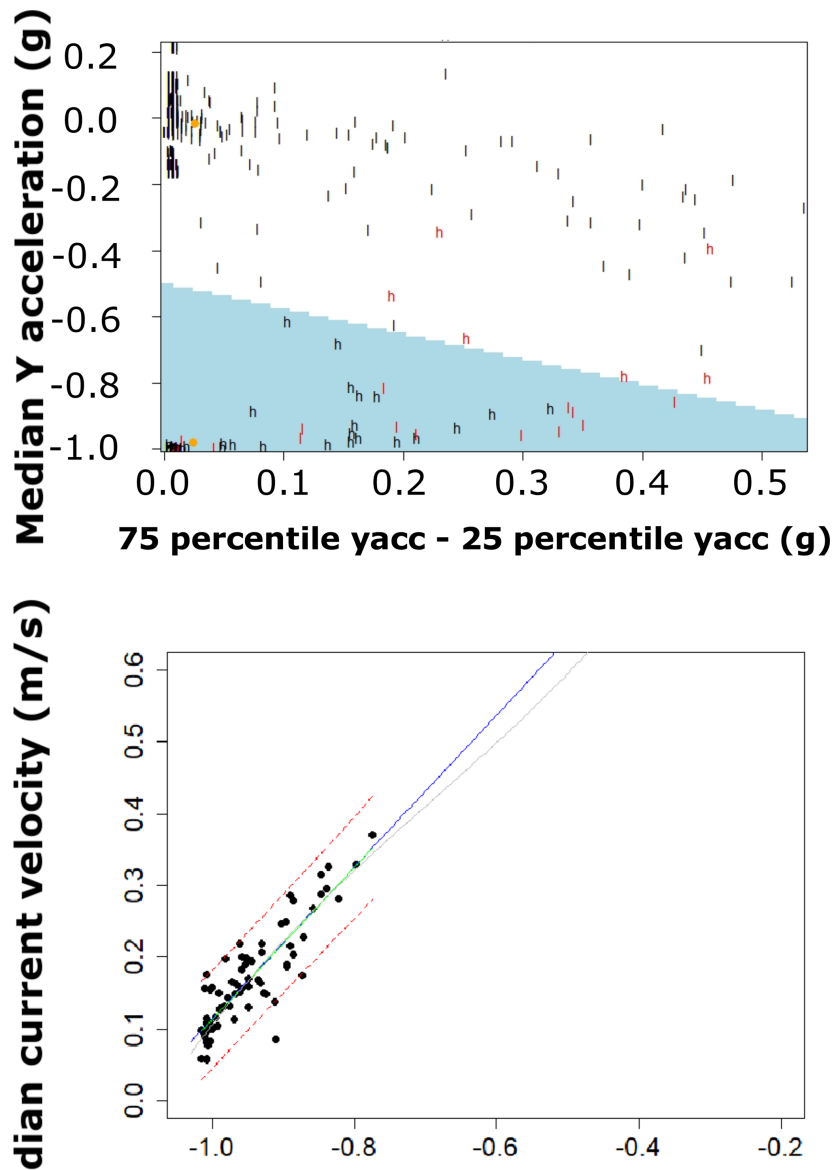

\section{Median y acceleration (g)}

Figure A2. Calibration of $10 \mathrm{~s}$ measurement interval data for $15 \mathrm{~min}$ time steps. (a) Linear discriminant analysis for North Sumatra dataset (B11 and B12) using $10 \mathrm{~s}$ interval acceleration data and aggregation over $15 \mathrm{~min}$ time steps ( 1 is low tide, $\mathrm{h}$ is high tide, and red letters are false predictions). Additionally, the LDA group averages are indicated as orange dots. The $-0.5 y$ acceleration threshold to separate inundation from non-inundation time steps was applied for the $\mathrm{R}$ shiny application. Linear regression (blue line) provided the best fit for the median $y$-axis acceleration $\left[Y_{\text {acc }}(\mathrm{g})\right]$ against the measured current velocity of $\mathrm{B} 1\left[V_{\mathrm{cur}}\left(\mathrm{m} \mathrm{s}^{-1}\right)\right]$ for 15 min intervals: $V_{\text {cur }}=1.173+1.059 \cdot Y_{\text {acc }}$, $R_{\mathrm{adj}}=0.7724, P<0.05$. The grey line shows the $1 \mathrm{~Hz}$ deployment regression line of Fig. 3 and the green line the predictions within the measured range of values.

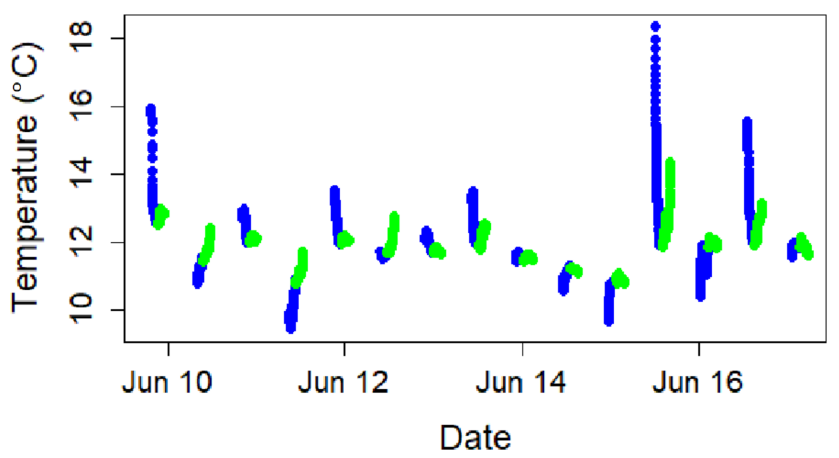

Figure A3. Time series example of temperature data at the Bay of Fundy Mini Buoy L2. Measured temperature during inundation by the Hobo data logger fixed to the top of the Mini Buoy L2. Colours indicate first and second half of inundation. 
Code availability. Code is available on GitHub at https://doi.org/10.5281/zenodo.4304146 (Balke, 2021a).

1. Mini Buoy R shiny app code (.R)

2. Mini Buoy Manual.

Zenodo repository: https://doi.org/10.5281/zenodo.4521304 (Balke et al., 2021).

1. Readme file

2. Aquadopp data (.dia):

2.1. North Sumatra

2.2. Bay of Fundy

3. Mini Buoy data (.csv):

3.1. Bay of Fundy: Mini Buoy acceleration L1-8 and temperature and light data

3.2. North Sumatra study site: Mini Buoy acceleration B1-16

3.3. North Sumatra additional sites (.csv)

- Open coast, Percut Sei Tuan

- Abandoned pond 1, Percut Sei Tuan non-tidal

- Abandoned pond 2, Percut Sei Tuan (study site)

- Restoration pond, Belawan

- Channel (B1)

4. Animations of inundation and velocity predictions (mp4, gif):

4.1. Bay of Fundy animation of current velocities at $10 \mathrm{~min}$ time steps, arbitrary scale for the bars (.gif)

4.2. Inundation animation of the North Sumatra field site for two tidal cycles: (.mp4)

5. Mini Buoy application screenshots.

Data availability. The R shiny app can be used directly online under https://mangroverestoration.shinyapps.io/MiniBuoyApp/ (last access: 9 March 2021).

Author contributions. TB designed the Mini Buoy, carried out the data analysis and coding of the $\mathrm{R}$ shiny app, and led the writing of the manuscript. TB and MB carried out fieldwork in Indonesia. TB and GLC carried out fieldwork at the Bay of Fundy. CS assisted with hydrodynamic analyses for the Bay of Fundy dataset. TB, AV, $\mathrm{CS}, \mathrm{GLC}, \mathrm{CL}$, and MB jointly wrote and improved the final paper.

Competing interests. The authors declare that they have no conflict of interest.

Acknowledgements. Thorsten Balke and Alejandra Vovides acknowledge NERC grant NE/P014127/1 for financial support. Thorsten Balke acknowledges the Early Career Mobility Scheme of the University of Glasgow and the British Society for Geomorphology for additional financial support to conduct fieldwork at the Bay of Fundy. Thorsten Balke and Cai Ladd acknowledge Living Deltas NE/S008926/1. Mohammad Basyuni acknowledges DIPI-LPDP grant NE/P014127.1 for financial support. We thank
Margaret Kalacska for loan of the Emlid DGPS rover. We thank Bejo Slamet, Nurdin Sulistiyono, Yunta Bimantra, Riska Amelia, Muttia Chandra, and Nur Indah Lestari for help with fieldwork at Percut Sei Tuan. We thank Zulkifli and Legiman for allowing us to access the former aquaculture ponds at Percut Sei Tuan. We thank Yagasu for allowing us to access their restoration site at Belawan.

Financial support. This research has been supported by UK Research and Innovation (grant nos. NE/P014127/1 and NE/S008926/1).

Review statement. This paper was edited by Hubert H. G. Savenije and reviewed by two anonymous referees.

\section{References}

Akeila, E., Salcic, Z., and Swain, A.: Smart Pebble for Monitoring Riverbed Sediment Transport, IEEE Sens. J., 10, 1705-1717, https://doi.org/10.1109/JSEN.2010.2046726, 2010.

Albers, T. and Schmitt, K.: Dyke design, floodplain restoration and mangrove co-management as parts of an area coastal protection strategy for the mud coasts of the Mekong Delta, Vietnam, Wetl. Ecol. Manage., 23, 991-1004, https://doi.org/10.1007/s11273015-9441-3, 2015.

Balke, T.: Mini Buoy application for mangrove restoration hydrological site suitability assessment, Zenodo, https://doi.org/10.5281/zenodo.4304146, 2021a.

Balke, T.: Mini Buoy app, available at: https://mangroverestoration. shinyapps.io/MiniBuoyApp/ (last access: 9 March 2021), 2021b.

Balke, T., Bouma, T., Horstman, E., Webb, E., Erftemeijer, P., and Herman, P.: Windows of opportunity: thresholds to mangrove seedling establishment on tidal flats, Mar. Ecol. Prog. Ser., 440, 1-9, https://doi.org/10.3354/meps09364, 2011.

Balke, T., Herman, P. M. J., and Bouma, T. J.: Critical transitions in disturbance-driven ecosystems: identifying Windows of Opportunity for recovery, J. Ecol., 102, 700-708, https://doi.org/10.1111/1365-2745.12241, 2014.

Balke, T., Swales, A., Lovelock, C. E., Herman, P. M. J., and Bouma, T. J.: Limits to seaward expansion of mangroves: Translating physical disturbance mechanisms into seedling survival gradients, J. Exp. Mar. Biol. Ecol., 467, 16-25, https://doi.org/10.1016/j.jembe.2015.02.015, 2015.

Balke, T., Vovides, A., Schwarz, C., Chmura, G. L., Ladd, C., and Basyuni, M.: Monitoring of tides in coastal wetlands with the 'Mini Buoy': applications for mangrove restoration, Zenodo, https://doi.org/10.5281/zenodo.4521304, 2021.

Beanland, E., Main, L. C., Aisbett, B., Gastin, P., and Netto, K.: Validation of GPS and acceleroeter technology in swimming, J. Sci. Med. Soprt., 17, 234-238, https://doi.org/10.1016/j.jsams.2013.04.007, 2014.

Bockelmann, A.-C., Bakker, J. P., Neuhaus, R., and Lage, J.: The relation between vegetation zonation, elevation and inundation frequency in a Wadden Sea salt marsh, Aquat. Bot., 73, 211-221, https://doi.org/10.1016/S0304-3770(02)00022-0, 2002.

Bouma, T. J., Temmerman, S., Duren, L. A., Martini, E., Vandenbruwaene, W., Callaghan, D. P., Balke, T., Biermans, G., 
Klaassen, P. C., Steeg, P., Dekker, F., Koppel, J., Vries, M. B., and Herman, P. M. J.: Organism traits determine the strength of scale-dependent bio-geomorphic feedbacks: A flume study on three intertidal plant species, Geomorphology, 180-181, 57-65, https://doi.org/10.1016/j.geomorph.2012.09.005, 2013.

Chang, W., Joe Cheng, J. J. A., Xie, Y., and McPherson, J.: shiny: Web Application Framework for R, available at: https://CRAN. R-project.org/package=shiny (last access: 9 March 2021), 2020.

Dale, P., Knight, P., and Dwyer, P.: Mangrove rehabilitation: a review focusing on ecological and institutional issues, Wetl. Ecol. Manage., 229, 587-604, https://doi.org/10.1007/s11273014-9383-1, 2014.

Delgado, P., Hensel, P. F., Jiménez, J. A., and Day, J. W.: The importance of propagule establishment and physical factors in mangrove distributional patterns in a Costa Rican estuary, Aquat. Bot., 71, 157-178, https://doi.org/10.1016/S03043770(01)00188-7, 2001.

Figurski, J. D., Malone, D., Lacy, J. R., and Denny, M.: An inexpensive instrument for measuring wave exposure and water velocity: Measuring wave exposure inexpensively, Limnol. Oceanogr. Meth., 9, 204-214, https://doi.org/10.4319/lom.2011.9.204, 2011.

Hansen, A. B., Carstensen, S., Christensen, D. F., and Aagaard, T.: Performance Of A Tilt Current Meter In The Surf Zone, Coast. Dynam., 218, 944-954, 2017.

Jiménez, J. A., Sauter, K., and Jimenez, J. A.: Structure and Dynamics of Mangrove Forests along a Flooding Gradient, Estuaries, 14, 49, https://doi.org/10.2307/1351981, 1991.

Koch, E. W., Ailstock, M. S., Booth, D. M., Shafer, D. J., and Magoun, A. D.: The Role of Currents and Waves in the Dispersal of Submersed Angiosperm Seeds and Seedlings, Restor. Ecol., 18, 584-595, https://doi.org/10.1111/j.1526100X.2010.00698.x, 2009.

Kodikara, K. A. S., Mukherjee, N., Jayatissa, L. P., DahdouhGuebas, F., and Koedam, N.: Have mangrove restoration porjects worked? An independent study in Sri Lanka, Restor. Ecol., 25, 705-716, 2017.

Krauss, K. W., Lovelock, C. E., McKee, K. L., LópezHoffman, L., Ewe, S. M. L., and Sousa, W. P.: Environmental drivers in mangrove establishment and early development: A review, Aquat. Bot., 89, 105-127, https://doi.org/10.1016/j.aquabot.2007.12.014, 2008.

Lewis, R. R.: Ecological engineering for successful management and restoration of mangrove forests, Ecol. Eng., 24, 403-418, https://doi.org/10.1016/j.ecoleng.2004.10.003, 2005.

Lewis, R. R. and Brown, B. M.: Ecological Mangrove Rehabilitation A Field Manual for Practitioners, 3rd Edn., Canadian International Development Agency, USAID, Oxfam, 2014.

MacDonald, G. A.: A review of low cost accelerometers for vehicle dynamics, Sens. Actuat. Phys., 21, 303-307, https://doi.org/10.1016/0924-4247(90)85060-H, 1990.

Matthijs, S., Tack, J., Van Speybroeck, D., and Koedam, N.: Mangrove species zonation and soil redox state, sulphide concentration and salinity in Gazi Bay (Kenya), a preliminary study, Mangrov. Salt Marsh., 3, 243-249, 1999.

Mullarney, J., Norris, B., Bryan, K., Fricke, A., Sandwell, D., and Culling, D.: A Question of Scale: How Turbulence Around Aerial Roots Shapes the Seabed Morphology in Man- grove Forests of the Mekong Delta, Oceanography, 30, 34-47, https://doi.org/10.5670/oceanog.2017.312, 2017.

Passfield, L., Hopker, J. G., Jobson, S., Friel, D., and Zabala, M.: Knowledge is power: issues of measuring training and performance in cycling, J. Sports Sci., 35, 1426-1434, https://doi.org/10.1080/02640414.2016.1215504, 2017.

Pennings, S. C. and Callaway, R. M.: Salt Marsh Plant Zonation: The Relative Importance of Competition and Physical Factors, Ecology, 73, 681-690, https://doi.org/10.2307/1940774, 1992.

Primavera, J. H. and Esteban, J. M.: A.: A review of mangrove rehabilitation in the Philippines: successes, failures and future prospects, Wetl. Ecol. Manage., 16, 345-358, https://doi.org/10.1007/s11273-008-9101-y, 2008.

Proisy, C., Viennois, G., Sidik, F., Andayani, A., Enright, J. A., Guitet, S., Gusmawati, N., Lemonnier, H., Muthusankar, G., Olagoke, A., Prosperi, J., Rahmania, R., Ricout, A., Soulard, B., and Suhardjono: Monitoring mangrove forests after aquaculture abandonment using time series of very high spatial resolution satellite images: A case study from the Perancak estuary, Bali, Indonesia, Mar. Pollut. Bull., 131, 61-71, https://doi.org/10.1016/j.marpolbul.2017.05.056, 2018.

Schwarz, C., Gourgue, O., Belzen, J., Zhu, Z., Bouma, T. J., Koppel, J., and Temmerman, S.: Self-organization of a biogeomorphic landscape controlled by plant life-history traits, Nat. Geosci., 11, 672-677, https://doi.org/10.1038/s41561-018-0180-y, 2018.

Silvestri, S., Defina, A., and Marani, M.: Tidal regime, salinity and salt marsh plant zonation, Estuar. Coast. Shelf Sci., 62, 119-130, https://doi.org/10.1016/j.ecss.2004.08.010, 2005.

Temmerman, S., Bouma, T. J., Koppel, J., Wal, D., De Vries, M. B., and Herman, P. M. J.: Vegetation causes channel erosion in a tidal landscape, Geology, 35, 631-634, 2007.

Van der Stocken, T., De Ryck, D. J. R., Balke, T., Bouma, T. J., Dahdouh-Guebas, F., and Koedam, N.: The role of wind in hydrochorous mangrove propagule dispersal, Biogeosciences, 10, 3635-3647, https://doi.org/10.5194/bg-10-3635-2013, 2013.

van Loon, A. F., Dijksma, R., and van Mensvoort, M. E. F.: Hydrological classification in mangrove areas: A case study in Can Gio, Vietnam, Aquat. Bot., 87, 80-82, https://doi.org/10.1016/j.aquabot.2007.02.001, 2007.

Venables, W. N. and Ripley, B. D.: Modern Applied Statistics with $S$, 4th Edn., Springer, New York, 2002.

Weihs, C., Ligges, U., Luebke, K., and Raabe, N.: klaR Analyzing German Business Cycles, edited by: Baier, D., Decker, R., and Schmidt-Thieme, L., Springer-Verlag, Berlin, 2005.

Wiehe, P. O.: A Quantitative Study of the Influence of Tide Upon Populations of Salicornia Europea, J. Ecol., 23, 323-333, https://doi.org/10.2307/2256124, 1935.

Wodehouse, D. C. J. and Rayment, M. B.: Mangrove area and propagule number planting targets produce sub-optimal rehabilitation and afforestation outcomes, Estuar. Coast. Shelf Sci., 222, 91-102, https://doi.org/10.1016/j.ecss.2019.04.003, 2019.

Wolters, M., Garbutt, A., and Bakker, J. P.: Salt-marsh restoration: evaluating the success of de-embankments in north-west Europe, Biol. Conserv., 123, 249-268, https://doi.org/10.1016/j.biocon.2004.11.013, 2005.

Worthington, T. and Spalding, M.: Mangrove Restoration Potential: A global map highlighting a critical opportunity, The Nature Conservancy, available at: https://oceanwealth.org/wp-content/ 
uploads/2019/02/MANGROVE-TNC-REPORT-FINAL.31.10. LOWSINGLES.pdf (last access: 9 March 2021), 2018.

Xiao, D., Zhang, C., Zhang, L., Zhu, Z., Tian, K., and Gao, W.: Seed dispersal capacity and post-dispersal fate of the invasive Spartina alterniflora in saltmarshes of the Yangtze Estuary, Estuar. Coast. Shelf Sci., 169, 158-163, https://doi.org/10.1016/j.ecss.2015.11.032, 2016.
Zaldivar-Jimenez, M. A., Herrera-Silveira, J. A., Teutli-Hernandez, C., Comin, F. A., Andrade, J. L., Molina, C. C., and Ceballos, R. P.: Conceptual Framework for Mangrove Restoration in the Yucatan Peninsula, Ecol. Restor., 28, 333-342, https://doi.org/10.3368/er.28.3.333, 2010. 